\title{
Formulasi Sediaan Krim Dari Ekstrak Kulit Pisang Kapas (Musa paradisiaca Linn).
}

\author{
Dananirroh $^{1}$, Urmatul Waznah ${ }^{2 *}$, W Wirasti $^{3}$, S Slamet $^{4}$ \\ 1,2,3,4Program Studi Sarjana Farmasi, Universitas Muhammadiyah Pekajangan Pekalongan, \\ Indonesia \\ *email: urmatul.apoteker@gmail.com
}

\begin{abstract}
Musa paradisiaca Linn, also known as the banana plant in Indonesia, is a herbaceous plant that belongs to the Musaceaa family. Cotton banana peel (Musa paradisiaca Linn.) can be used as a wound medicine. For use, it is still simple, namely by applying the inside of the banana peel to the injured body part, and by scraping the banana peel from the inside to bandage the wound. For this reason, it is necessary to develop a dosage form of this cotton banana peel so that it is easier and provides comfort in its use. Purpose: To find out the skin of cotton banana (Musa paradisiaca Linn) is formulated in cream preparations. The method in this study was experimental, the sample was extracted by maceration using $96 \%$ ethanol as solvent. The viscous extract obtained was used at concentrations of $0.08 \%, 0.10 \%$, and $0.12 \%$. The results showed that cotton banana peel extract (Musa paradisiaca Linn) could be made as a cream and fulfilled the physical evaluation of the preparation. The results of the homogeneity test were that the preparations were made homogeneous, the $\mathrm{pH}$ of the cream was obtained at $\mathrm{pH} \mathrm{5-7}$ still fulfilling the skin $\mathrm{pH}$ range of 4-7, the adhesion test results obtained more than 5 seconds, the dispersion test results obtained $6-7 \mathrm{~cm}$, the viscosity test at formula I is $3564-4253$ cPas, Formula II is $4042-4746$ cPas, Formula III is $4466-5254$ cPas. The conclusion of this study, the formulation of the ethanol extract cream of cotton banana peel (Musa paradisiaca Linn) met the requirements for physical evaluation of the preparation including homogeneity test, $\mathrm{pH}$ test, organoleptic test, dispersibility test, adhesion test, viscosity test and stability test.
\end{abstract}

Keywords: Formulation, banana peel, cream, evaluation.

\begin{abstract}
Abstrak
Musa paradisiaca Linn atau dikenal dengan nama tumbuhan pisang di Indonesia adalah tumbuhan herba yang termasuk dalam keluarga Musaceaa. Kulit buah pisang kapas (Musa paradisiaca Linn.) dapat digunakan sebagai obat luka. Untuk penggunaan masih sederhana yaitu dengan mengoleskan bagian dalam dari kulit buah pisang pada bagian tubuh yang luka, dan dengan cara mengorek kulit buah pisang dari dalam untuk membalut luka. Untuk itu perlu adanya pengembangan bentuk sediaan dari kulit pisang kapas ini sehingga lebih memudahkan dan memberikan kenyamanan dalam penggunaannya. Tujuan Untuk mengetahui kulit buah pisang kapas (Musa paradisiaca Linn) diformulasikan dalam sediaan krim. Metode pada penelitian ini dilakukan secara eksprimental, sampel di ekstraksi dengan cara maserasi dengan menggunakan pelarut etanol $96 \%$. Ekstrak kental yang diperoleh digunakan pada konsentrasi $0.08 \%, 0.10 \%$, dan $0.12 \%$. Hasil penelitian menunjukkan bahwa ekstrak kulit pisang kapas (Musa paradisiaca Linn) dapat dibuat sebagai krim dan memenuhi evaluasi fisik sediaan. Hasil uji homogenitas bahwa sediaan yang dibuat homogen, pH krim diperoleh pH 5-7 masih memenuhi kisaran pH kulit 4-7, uji daya lekat hasil yang diperoleh lebih dari 5 detik, uji daya sebar hasil yang diperoleh $6-7 \mathrm{~cm}$, uji viskositas pada formula I yaitu 3564 - 4253 cPas, Formula II yaitu 4042 - 4746 cPas, Formula III yaitu 4466 - 5254 cPas. Kesimpulan pada penelitian ini, formulasi sediaan krim ekstrak etanol kulit pisang kapas (Musa paradisiaca Linn) memenuhi syarat evaluasi fisik sediaan meliputi uji homogenitas, uji $\mathrm{pH}$, uji organoleptis, uji daya sebar, uji daya lekat, uji viskositas dan uji stabilias.
\end{abstract}

Kata kunci: Formulasi, kulit pisang, krim, evaluasi. 


\section{Prosiding Seminar Nasional Kesehatan Lembaga Penelitian dan Pengabdian Masyarakat Universitas Muhammadiyah Pekajangan Pekalongan

\section{Pendahuluan}

Indonesia salah satu negara yang memiliki keanekaragaman hayati tertinggi di dunia. Keanekaragaman hayati tersebut adalah tumpuan hidup masyarakat sebagai sumber pangan,pakan, bahan baku industri, dan obat-obatan. Menurut Kementerian Pertanian (2015) menyatakan pisang yaitu salah satu buah yang sangat popular di masyarakat Indonesia karena mudah ditemukan dan tersedia dalam berbagai jenis. Tanaman serba guna, mulai dari akar sampai dari daun salah satunya adalah tanaman pisang. Tanaman ini juga sejak lama sudah dimanfaatkan sebagai obat alternatif. Salah satunya untuk mengobati berbagai macam penyakit seperti mengurangi gejala asma, mengurangi penyakit leukemia, membantu memperkuat tulang, meredakan depresi, pelindung lambung, menyehatkan mata, dan menjaga kelembab kulit [1].

Penggunaan kulit pisang terutama pada penelitian ini, karena pisang merupakan tanaman yang tersebar luas dengan jumlah yang tinggi di Indonesia, sehingga mudah didapat. Selain itu, untuk memanfaatkan limbah kulit pisang yang biasanya terbuang sehingga akan meningkatkan nilai ekonomi kulit pisang [2].

Salah satu spesiesnya adalah tanaman pisang kapas yang sudah dikenal dan dibudidayakan oleh masyarakat serta memiliki berbagai manfaat seperti buahnya dapat dimakan langsung maupun diolah menjadi berbagai olahan makanan, daun pisang biasanya dipakai keperluaan untuk rumah tangga, batang dan kulit pun dimanfaatkan sebagai pakan ternak. Kulit pisang mengandung flavonoid menghambat pertumbuhan fibrolast sehingga perawatan luka dapat maksimal. Selain itu, kandungan kulit pisang adalah steroid dan saponin yang berfungsi sebagai zat untuk mengatasi luka inflamasi dan sebagai antioksidan [3].

Menurut pengalaman, masyarakat Nias khususnya di Desa Hiliamaetaluo menggunakan kulit buah pisang sebagai obat luka. Untuk penggunaan masih sederhana yaitu dengan mengoleskan bagian dalam dari kulit buah pisang pada bagian tubuh yang luka, dan dengan cara mengorek kulit buah pisang dari dalam untuk membalut luka. Untuk itu perlu adanya pengembangan bentuk sediaan dari kulit pisang kapas ini sehingga lebih memudahkan dan memberikan kenyamanan dalam penggunaannya.

Krim adalah bentuk sediaan setengah padat, berupa emulsi yang mengandung air tidak kurang dari $60 \%$, dan dimaksudkan untuk pemakain luar. Krim juga merupakan obat yang digunakan sebagai obat luar yang dioleskan kebagian tubuh. $[4,5]$

Berdasarkan uraian diatas, peneliti tertarik untuk melakukan penelitian terhadap kulit buah pisang kapas (Musa paradisiaca Linn.) yang dijadikan dalam bentuk sediaan krim serta memberikan informasi kepada masyarakat bahwa limbah kulit pisang dapat dimanfaatkan menjadi sebuah sediaan farmasi yang berguna untuk masyarakat. Oleh karena itu peneliti tertarik melakukan penelitian terkait ekstrak etanol dengan menggunakan kulit buah pisang kapas (Musa paradisiaca Linn.) yang dibuat dalam sediaan krim. 


\section{Prosiding Seminar Nasional Kesehatan Lembaga Penelitian dan Pengabdian Masyarakat Universitas Muhammadiyah Pekajangan Pekalongan

\section{Metode}

\section{Alat dan Bahan}

Alat yang digunakan yaitu labu Erlenmeyer, waterbath, rotary evapotaror, alat-alat gelas lainnya, pH meter, pipet tetes, pipet ukur, pipet volume, cawan, lumping da waterbath.

Bahan-bahan yang akan digunakan yaitu Kulit pisang kapas, asam stearate, gliserin,propilen glikol, gliseril monostearat, TEA, nipasol, nipagin, aquadest, kloroform, asam sulfat, pereaksi-pereaksi Lieberman Buchard, mayer, dragendof,wagner, logam $\mathrm{Mg}, \mathrm{Hcl}$ dan $\mathrm{NaOH} 10 \%$.

\section{Persiapan dan Pengelolahan Sampel}

kulit diambil dari buah pisang kapas yang telah masak. Kulit pisang dipisahkan dari daging buahnya, di cuci dengan air mengalir untuk menghilangkan kotoran-kotoran yang melekat. Kemudian dilakukan perajangan, dirajang menjadi bagian-bagian yang lebih kecil. Setelah itu dilakukan proses pengeringan dengan panas sinar matahari dan ditutup menggunakan kain hitam agar panasnya merata. Kulit pisang yang telah kering kemudian disortasi kering lalu dihaluskan dengan blender hingga halus dan diayak dengan ayakan no 40 mesh hingga membentuk serbuk simplisia.

\section{Ekstraksi}

Sebanyak $500 \mathrm{gr}$ serbuk direndam 3 liter etanol. Kemudian di maserasi selama 5 hari dengan 1 jam pengadukan setiap hari dan dilakukan remaserasi selama 3 hari. filtrat hasil maserasi dan remaserasi digabungkan dan diuapkan menggunakan rotary evaporator, selanjutnya diuapkan kembali menggunakan waterbath untuk menghasilkan ekstrak yang lebih kental. ekstrak kental ditimbang dan diuji kadar airnya.

\section{Pembuatan Sediaan Krim Ekstrak Kulit Pisang Kapas ( Musa paradisiaca Linn).}

Tabel 2.1 Formula Krim Ekstrak Kulit Pisang Kapas (Musa paradisiaca Linn). Formula tersebut dari penelitian safitri, meta [6].

\begin{tabular}{ccccc}
\hline \multirow{2}{*}{ Komposisi } & \multicolumn{2}{c}{ Komposisi tiap formula \% (gram) } & \multirow{2}{*}{ Fungsi } \\
\cline { 2 - 4 } & Formula 1 & Formula 2 & Formula 3 & \\
\hline $\begin{array}{c}\text { Ekstrak kulit } \\
\text { pisang kapas } \\
\text { (Musa }\end{array}$ & $0,08 \%$ & $0,10 \%$ & $0,12 \%$ & Zat Aktif \\
Paradisiaca) & & & & \\
\hline Asam stearate & $12 \%$ & $12 \%$ & $12 \%$ & Pengemulsi \\
\hline Setil alkohol & $0,5 \%$ & $0,5 \%$ & $0,5 \%$ & Pengental \\
\hline TEA & $1 \%$ & $1 \%$ & $1 \%$ & Pengemulsi \\
\hline Nipagin & $0,1 \%$ & $0,1 \%$ & $0,1 \%$ & Pengawet \\
\hline Nipasol & $0,05 \%$ & $0,05 \%$ & $0,05 \%$ & Pengawet \\
\hline Gliserin & $2 \%$ & $2 \%$ & $2 \%$ & Humektan \\
\hline Aquadest & Ad 100 mL & Ad 100 mL & Ad 100 mL & Pelarut \\
\hline
\end{tabular}




\section{Prosiding Seminar Nasional Kesehatan Lembaga Penelitian dan Pengabdian Masyarakat Universitas Muhammadiyah Pekajangan Pekalongan

Disiapkan alat dan bahan-bahan yang akan digunakan. Ditimbang semua bahan yang akan digunakan. Fase minyak yaitu asam stearate, setil alcohol dan propil paraben/nipasol. Fase air yaitu TEA, gliserin, nipagin dan aquadest. Dipisahkan fase minyak dan fase air dipanaskan pada suhu $70^{\circ} \mathrm{C}$. Sesudah semuanya melebur, dimasukkan fase minyak sedikit demi sedikit ke dalam lumping panas yang sudah diisi dengan fase air, kemudian digerus hingga terbentuk basis krim. Setelah itu tambahkan ekstrak kulit pisang aduk hingga homogen. Terakhir masukan ke dalam wadah.

\section{Evaluasi Sediaan Fisik Krim}

Evaluasi Sediaan Fisik Krim meliputi uji organoleptic, uji pH, uji homogenitas, uji daya sebar, uji daya lekat, uji viskositas dan uji cycling test.

a. Uji organoleptic

Uji organoleptik dilakukan secara visual untuk melihat tampilan fisik sediaan dengan cara melakukan pengamatan terhadap warna, bau dan tekstur dari sediaan yang telah dibuat [3].

b. Uji pH

Sebanyak $1 \mathrm{gr}$ krim ekstrak dan diencerkan dengan aqudest sebanyak $10 \mathrm{~mL}$. Kemudian digunakan $\mathrm{pH}$ stick untuk melihat $\mathrm{pH}$. $\mathrm{pH}$ sediaan yang memenuhi kriteria pH kulit yaitu dalam interval 4,5-6,5 [3].

c. Uji Homogenitas

Uji homogenitas dilakukan untuk melihat apakah sediaan yang telah dibuat homogen atau tidak, dengan cara krim dioleskan pada kaca transparan dimana sediaan diambil secukupnya. Homogenitas ditunjukan dengan tidak adanya butiran kasar [7].

\section{d. Uji Daya Sebar}

Krim ditimbang sebanyak 0,5 gram dan diletakkan diatas kaca yang telah dilapisi kertas grafik, kemudian diletakkan sebuah petri di atasnya dan dibiarkan selama 1 menit, dihitung luas daerah yang diberikan sediaan. Selanjutnya diberi beban pada masing-masing sediaan berturut-turut sebesar 50, 100, dan $250 \mathrm{~g}$ dibiarkan selama 60 detik selanjutnya dihitung luas sediaan yang dihasilkan [3].

\section{e. Uji Daya Lekat}

Sebanyak 0,5 g krim dioleskan diatas gelas obyek yang sudah diketahui luasnya. Diletakkan gelas obyek yang lain pada krim tersebut kemudian ditekan dengan beban $1 \mathrm{~kg}$ selama 5 menit. Gelas objek tersebut dipasang pada alat uji kemudian di beri beban seberat $80 \mathrm{~g}$ dan dicatat waktu hingga kedua gelas objek terpisah [3].

\section{f. Uji Viskositas}

Viskositas sediaan krim diukur menggunakan viscometer brookfield, yaitu dengan memasang spindle yang sesuai pada alat kemudian dicelupkan ke dalam sediaan sampai batas tertentu, alat dinyalakan dengan kecepatan $60 \mathrm{rpm}$ tunggu sampai menunjukkan angka yang stabil [8]. 


\section{g. Uji Stabilitas}

Uji stabilitas dilakukan dengan metode cycling test. Krim disimpan pada suhu \pm $4^{\circ} \mathrm{C}$ selama 24 jam, kemudian pada suhu $40{ }^{\circ} \mathrm{C}$ selama 24 jam. Pengujian dilakukan selama 6 siklus, tiap siklus dilihat perubahan fisik krim yang meliputi uji organoleptic, homogenitas, pH dan daya sebar [9].

\section{Hasil dan Pembahasan}

\section{Hasil}

\section{Evaluasi Sediaan}

a. Uji organoleptis

Tabel 3.1 Hasil organoleptis

\begin{tabular}{cccccc}
\hline \multirow{2}{*}{$\begin{array}{c}\text { Formul } \\
\text { a }\end{array}$} & Parame & \multicolumn{5}{c}{ Hari ke - } \\
\cline { 3 - 6 } F1 & ter & 1 & 7 & 14 & 21 \\
\cline { 2 - 6 } & warna & cream & cream & cream & cream \\
\cline { 2 - 6 } & bau & khas & khas & khas & khas \\
\cline { 2 - 6 } F2 & tekstur & semi padat & semi padat & semi padat & semi padat \\
\cline { 2 - 6 } & warna & cream & cream & cream & cream \\
\cline { 2 - 6 } & tekstur & semi padat & semi padat & semi padat & semi padat \\
\hline \multirow{2}{*}{ F3 } & warna & cream pekat & cream pekat & cream pekat & cream pekat \\
\cline { 2 - 6 } & bau & khas & khas & khas & khas \\
\cline { 2 - 6 } & tekstur & semi padat & semi padat & semi padat & semi padat \\
\hline
\end{tabular}

b. Uji Ph

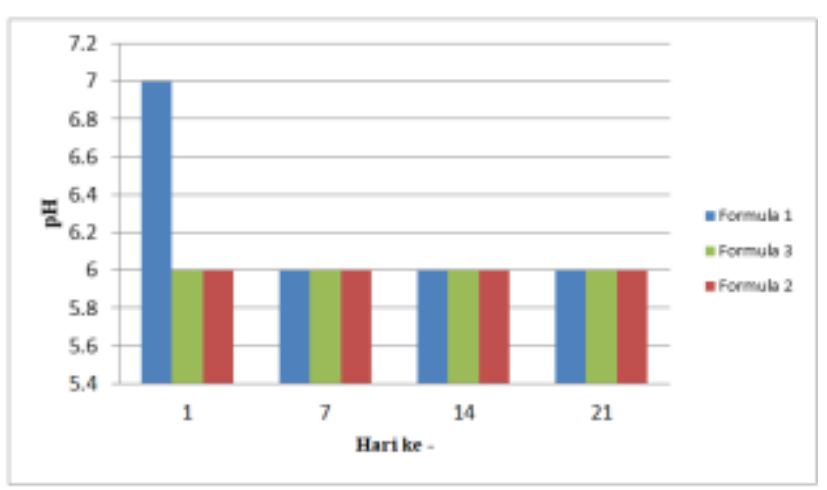

Gambar 3.1 grafik uji pH sediaan

c. Uji homogenitas

Tabel 3.2 Hasil uji homogenitas

\begin{tabular}{cccc}
\hline Hari & \multicolumn{3}{c}{ Hasil } \\
\cline { 2 - 4 } ke & Formula 1 & Formula 2 & Formula 3 \\
\hline 1 & Homogen & Homogen & Homogen \\
7 & Homogen & Homogen & Homogen \\
14 & Homogen & Homogen & Homogen \\
21 & Homogen & Homogen & Homogen \\
\hline
\end{tabular}


d. Uji Daya sebar

Tabel 3.3 Hasil uji daya sebar

\begin{tabular}{c|c|c|c}
\hline \multirow{2}{*}{$\begin{array}{c}\text { Hari } \\
\text { ke }\end{array}$} & Formula 1 & Formula 2 & Formula 3 \\
\cline { 2 - 4 } & $4,35-7 \mathrm{~cm}$ & $4,2-7 \mathrm{~cm}$ & $4,3-6,95 \mathrm{~cm}$ \\
\hline 1 & $3,45-6,6 \mathrm{~cm}$ & $3,7-6,9 \mathrm{~cm}$ & $4-6,9 \mathrm{~cm}$ \\
14 & $3,4-6,6 \mathrm{~cm}$ & $3,2-6,4 \mathrm{~cm}$ & $3,8-6,9 \mathrm{~cm}$ \\
21 & $3,25-6,55 \mathrm{~cm}$ & $3,1-6,3 \mathrm{~cm}$ & $3,4-6,4 \mathrm{~cm}$ \\
\hline
\end{tabular}

e. Daya lekat

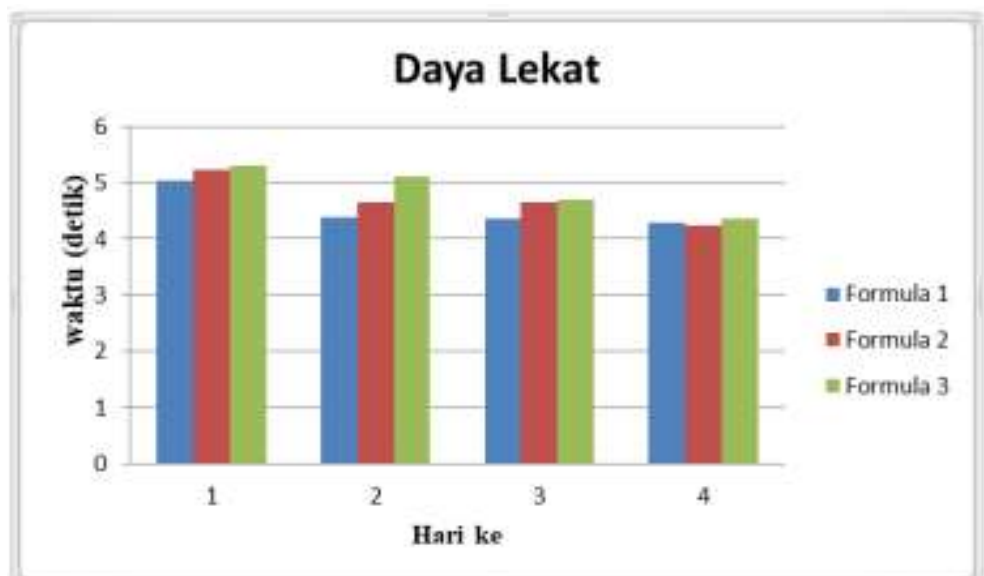

Gambar 3.2 Grafik hasil uji daya lekat

f. Uji viskositas

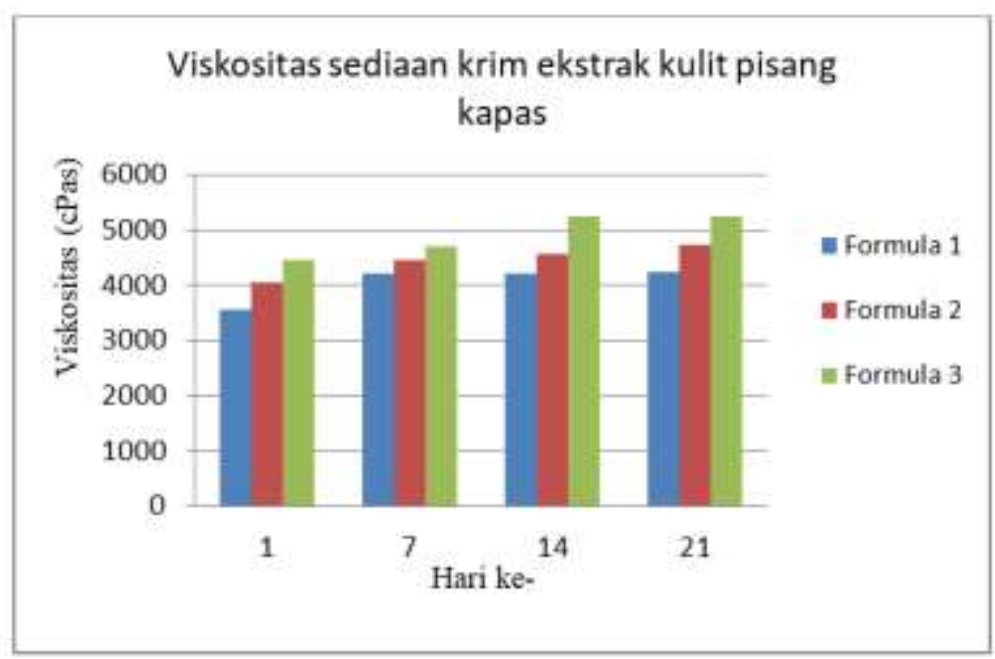

Gambar 3.3 Grafik hasil uji viskositas 
g. Uji Stabilitas

Cycling test organoleptis dan homogenitas

Tabel 3.4 Hasil Pemeriksaan Cycling Test Organoleptis

\begin{tabular}{cccc}
\hline \multirow{2}{*}{ Formula } & \multirow{2}{*}{ Parameter } & \multicolumn{2}{c}{ Parameter Cycling Test } \\
& Sebelum & Sesudah \\
\hline \multirow{3}{*}{1} & Warna & Cream & Cream \\
\cline { 2 - 4 } & Bau & khas & khas \\
\cline { 2 - 4 } & Bentuk & Semipadat & Semipadat \\
\cline { 2 - 4 } & Homogenitas & Homogen & Homogen \\
\hline \multirow{3}{*}{2} & Warna & Cream & Cream \\
\cline { 2 - 4 } & Bau & khas & khas \\
\cline { 2 - 4 } & Bentuk & Semipadat & Semipadat \\
\cline { 2 - 4 } & Homogenitas & Homogen & Homogen \\
\hline \multirow{3}{*}{3} & Warna & Cream pekat & Cream pekat \\
\cline { 2 - 4 } & Bau & khas & khas \\
\cline { 2 - 4 } & Bentuk & Semipadat & Semipadat \\
\cline { 2 - 4 } & Homogenitas & Homogen & Homogen \\
\hline
\end{tabular}

Cycling Test pH

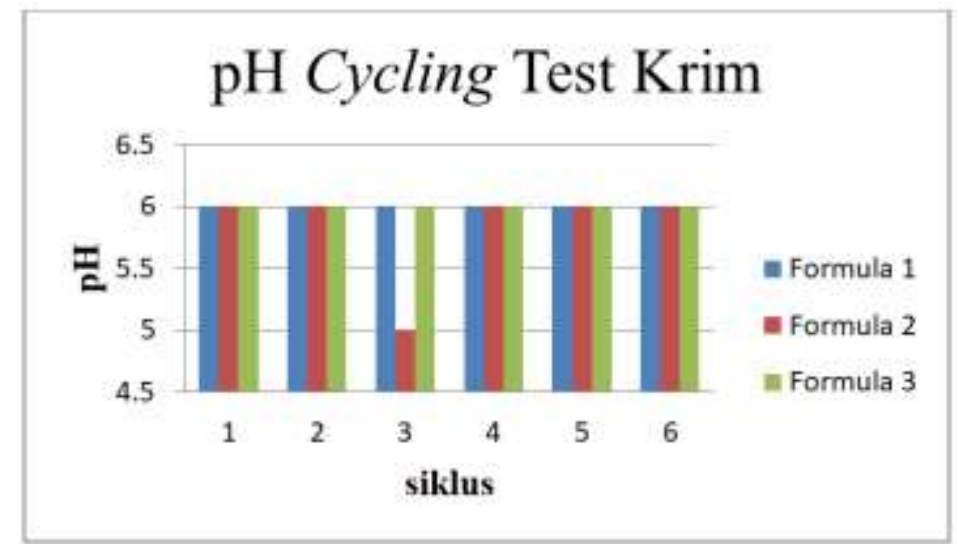

Gambar 3.4 Grafik hasil cycling test pH

Cycling Test daya sebar

Tabel 3.5 Hasil cycling test daya sebar

\begin{tabular}{c|c|c|c}
\hline \multirow{2}{*}{ Siklus } & \multicolumn{3}{|c}{ Formula } \\
\cline { 2 - 4 } & Formula I & Formula II & Formula III \\
\hline 1 & $4,15-6,85 \mathrm{~cm}$ & $3,95-7 \mathrm{~cm}$ & $3,65-6,85 \mathrm{~cm}$ \\
2 & $3,9-6,65 \mathrm{~cm}$ & $3,5-6,75 \mathrm{~cm}$ & $3,6-6,75 \mathrm{~cm}$ \\
3 & $3,8-6,6 \mathrm{~cm}$ & $3,5-6,5 \mathrm{~cm}$ & $3,55-6,55 \mathrm{~cm}$ \\
4 & $3,6-6,3 \mathrm{~cm}$ & $3,7-6,1 \mathrm{~cm}$ & $3,55-6,35 \mathrm{~cm}$ \\
5 & $3,4-6,05 \mathrm{~cm}$ & $3,35-5,65 \mathrm{~cm}$ & $3,1-6,2 \mathrm{~cm}$ \\
6 & $3,1-5,7 \mathrm{~cm}$ & $2,8-5,7 \mathrm{~cm}$ & $3,1-5,65 \mathrm{~cm}$ \\
\hline
\end{tabular}




\section{Prosiding Seminar Nasional Kesehatan Lembaga Penelitian dan Pengabdian Masyarakat Universitas Muhammadiyah Pekajangan Pekalongan

\section{Pembahasan}

\section{Pengelolahan simplisia}

Kulit buah pisang kapas (Musa paradisiaca Linn.) yang didapatkan memiliki berat basah sebanyak $5000 \mathrm{~g}$, setelah melalui beberapa proses pembuatan simplisia didapatkan berat kering simplisia kulit buah pisang kapas (Musa paradisiaca Linn.) sebesar 940 gram, setelah proses pengeringan dan menjadi bentuk serbuk memiliki kadar air sebesar 10,6\%. Kadar air tersebut masih memenuhi kadar air simplisia yang tidak kurang dari $10 \%$.

\section{Ekstraksi}

Bobot ekstrak kental kulit buah pisang kapas (Musa paradisiaca Linn.) yang diperoleh yaitu 39,25 gram dengan rendemen yaitu 7,85\%, rendemen ekstrak dapat dihitung berdasarkan perbandingan bobot ekstrak dengan bobot awal serbuk simplisia dikalikan dengan 100\%. Ekstrak Kulit Buah Pisang Kapas (Musa paradisiaca Linn.) memiliki kadar air 0,5\%, kadar air tersebut memenuhi persyaratan yang ditentukan yaitu kurang dari $10 \%$, karena jika lebih dari $10 \%$ hal tersebut akan mempengaruhi kondisi ekstrak selama penyimpanan seperti rentan untuk ditumbuhi jamur [10].

\section{Evaluasi Sediaan}

\section{a. Uji organoleptis}

Tujuan dari uji organoleptis yaitu untuk melihat tampilan fisik suatu sediaan dengan pengamatan terhadap warna, bau dan tekstur. Krim yang dihasilkan sebaiknya mempunyai warna yang menarik,bau yang menyenangkan serta kekentalan yang cukup agar nyaman pada saat digunakan. Hasil dapat dilihat pada tabel 4.2. Dari tabel 4.2, hasil uji organoleptis F1 dan F2 dari hari ke-1 sampai ke21 mempunyai warna cream, aroma khas pisang dan berbentuk semipadat. Untuk F3 dari hari ke 1 sampai ke 21 mempunyai karakteristik warna cream pekat, aroma khas pisang dan bentuk semipadat. Maka dapat disimpulkan bahwa F1-F3 pada hari ke-1 sampai ke-21 tidak ada perubahan warna, aroma dan bentuk pada masing-masing formula sehingga mempunyai organoleptis yang stabil selama pengamatan.

\section{b. Uji homogenitas}

Tujuan dari uji homogenitas adalah untuk melihat tercampurnya bahan-bahan krim secara merata serta terbebas dari partikel-partikel yang menggumpal agar tidak menimbulkan iritasi pada kulit ketika dioleskan secara topikal. Hasil uji homogenitas tertera pada tabel 4.3. Dari hasil uji homogenitas F1, F2 dan F3 dari hari ke-1 sampai ke-21 diperoleh hasil yang homogen, karena krim tercampur merata dan tidak terdapat butiran-butiran saat diletakan di kaca objek. Sehingga menunnjukan sediaan tersebut memiliki homogenitas yang stabil.

\section{c. Uji pH}

Tujuan dari pengujian pH krim yaitu untuk melihat tingkat keasaman dan kebasaan krim agar menjamin sediaan krim tidak menyebabkan iritasi pada kulit. Hasil uji pH dapat dilihat pada gambar 1 . Hasil pengamatan pada F1 hari ke-1 


\section{Prosiding Seminar Nasional Kesehatan Lembaga Penelitian dan Pengabdian Masyarakat Universitas Muhammadiyah Pekajangan Pekalongan

diperoleh $\mathrm{pH}$ sebesar 7, untuk F2 dan F3 diperoleh pH sebesar 6. Pada hari ke-7 sampai ke-21 untuk F1, F2 dan F3 didapatkan pH sebesar 6. Pengukuran pH dilakukan pengamatan pada hari ke-1 sampai ke-21 dengan menggunakan universal indicator $\mathrm{pH}$. Pengujian $\mathrm{pH}$ pada sediaan topikal adalah parameter fisik yang harus diuji, karena $\mathrm{pH}$ dapat menyebabkan efektivitas, stabilitas dan kenyamanan pengguna sediaan. Sediaan yang bersifat basa tidak termasuk kedalam kriteria rentang $\mathrm{pH}$ pada kulit, dimana $\mathrm{pH}$ kulit untuk topikal yaitu 4-7. Apabila jika $\mathrm{pH}$ basa akan mengakibatkan kulit terasa licin, cepat kering dan mempengaruhi elastisitas kulit. Sebaiknya jika sediaan bersifat asam dengan rentang dibawah 4-7, maka kulit mudah mengalami iritasi [11].

\section{d. Uji daya sebar}

Tujuan uji daya sebar pada sediaan krim yaitu menjamin pemerataan krim saat diaplikasikan pada kulit. Sediaan krim diharapkan memiliki kemampuan menyebar yang baik pada saat diaplikasikan ke kulit, sehingga dalam pengaplikasianya pada kulit tidak membutuhkan penekan yang berlebihan [12]. Hasil pengamatan 4.4 , dapat dilihat penurunan daya sebar krim setiap harinya, penurunan daya sebar ini disebabkan karena peningkatan viskositas sediaan krim. Hal tersebut disebabkan karena penambahan konsentrasi ekstrak pada krim dapat menurunkan luas penyebaran krim, sehingga semakin tinggi konsentrasi ekstrak pada krim maka luas permukaan krim semakin kecil. Daya sebar yang baik yaitu sekitar 5-7 sehingga krim dapat dengan mudah dioleskan pada kulit tanpa penekan yang kuat dengan jari tangan. Semakin mudah krim digunakan pada permukaan kulit maka krim yang kontak dengan permukaan kulit semakin luas serta zat aktif akan terdistribusi dengan baik [13].

\section{e. Uji daya lekat}

Tujuan dari uji daya lekat krim yaitu untuk mengetahui kemampuan sediaan krim bertahan pada permukaan kulit saat diaplikasikan. Daya lekat sediaan krim ini berhubungan dengan lamanya kontak antara sediaan krim dengan kulit, serta kenyamanan penggunaan sediaan krim. Krim yang baik mampu menjamin waktu kontak yang efektif dengan kulit sehingga tujuan penggunaannya tercapai [14]. Dari gambar 2. daya lekat sediaan krim ekstrak kulit pisang kapas (Musa paradisiaca Linn) untuk F1, F2 dan F3 diperoleh daya lekat dengan waktu 4-5 detik. Persyaratan daya lekat krim yang baik yaitu lebih dari 4 detik. Maka dapat disimpulkan bahwa sediaan krim kulit pisang kapas (Musa paradisiaca Linn) memenuhi persyaratan daya lekat krim yang baik.

\section{f. Uji viskositas}

Viskositas merupakan gambaran dari tahanan suatu benda cair untuk mengalir. Dilakukan uji viskositas dikarenakan sifat ini sangat penting dalam formulasi sediaan cair dan semipadat, karena untuk menentukan sifat dari sediaan dalam hal campuran dan sifat alirnya, baik pada saat pembuatan, dimasukan dalam kemasan, serta pada saat pemakaian; yaitu seperti konsistensi, daya sebar dan kelembaban. Berdasarkan hasil gambar 4.3 , uji viskositas dapat disimpulkan 
bahwa F1, F2 dan F3 mengalami peningkatan viskositas tiap minggunya. Viskositas yang disyaratkan oleh SNI 16-4399-1996 adalah $2000-50.000 \mathrm{cp}$. Viskositas meningkat seiring peningkatan konsentrasi ekstrak, sehingga semakin besar konsentrasi ekstrak yang dimasukkan kedalam sediaan maka semakin meningkat pula viskositasnya [11]. Viskositas krim akan berpengaruh pada kemampuan menyebar dipermukaan kulit, dimana semakin tinggi viskositasnya maka kemampuan menyebar pada permukaan kulit akan menurun [12].

\section{g. Uji cycling test}

Organoleptis dan Homogenitas Cycling test Krim

Berdasarkan hasil pengujian cycling test organoleptis dan homogenitas tidak ada perubahan pada sebelum dan sesudah cycling test. Hasil pemeriksaan cycling test organoleptis dan homogenitas tertera pada tabel 5.

$\mathrm{pH}$ Cycling test Krim

Berdasarkan hasil uji cycling test pada $\mathrm{pH}$ krim menunjukan $\mathrm{pH}$ tidak konstan atau terjadi perubahan. Pada siklus ke 3 Formula II pH yang dihasilkan yaitu 5 . Tetapi dengan $\mathrm{pH} 5$ tersebut masih memenuhi syarat, karena syarat rentang $\mathrm{pH}$ 4-7 [11]. Tidak adanya perubahan $\mathrm{pH}$ menandakan tidak adanya suatu reaksi atau kerusakan komponen di dalam sediaan tersebut sehingga $\mathrm{pH}$ tetap.

Daya sebar Cycling test Krim

Berdasarkan hasil tabel 4.6, sediaan krim untuk F1, F2 dan F3 memenuhi persyaratan daya sebar yang baik, karena masih masuk kedalam persyaratan daya sebar yang baik yaitu $5-7 \mathrm{~cm}$. Daya sebar yang baik dapat mengakibatkan kontak antara obat dengan kulit menjadi luas, sehingga absorbsinya berlangsung cepat [15].

\section{Kesimpulan}

Krim ekstrak kulit pisang kapas (Musa paradisiaca Linn) memenuhi persyaratan parameter kestabilan fisik meliputi uji organoleptis yaitu bentuk semipadat, bau khas, warna cream. Memiliki pH $5-7$ ( syarat 4-7), uji daya lekat hasil yang diperoleh lebih dari 5 detik (syarat lebih dari 4 detik), uji daya sebar hasil yang diperoleh $6-7$ cm (syarat $5-7 \mathrm{~cm}$ ), uji viskositas pada formula I yaitu $3564-4253$ cPas, Formula II yaitu 4042 - 4746 cPas, Formula III yaitu 4466 - 5254 cPas ( Syarat 2000 - 50000 cPas) dan uji cycling test ditandai dengan tidak adanya perubahan atau pemisahan sediaan selama 6 siklus.

\section{Referensi}

[1] Winarsi, H. (2011). Antioksidan Alami dan Radikal Bebas. Yogjakarta: Kanisius

[2] Anggraini ,S. (2016). Pengaruh Substitusi Tepung Pisang Kepom Putih pada Eggroll terhadap Kadar Vitamin C dan Daya Terima. Skripsi. Fakultas Ilmu Kesehatan. Universias Muhammadiyah Surakarta. 
[3] Azkiya, Z., Ariyani, H., \& Nugraha, T. (2017). Evaluasi Sifat Fisik Krim Jahe merah (Zingiber officinale Rosc.var. rubrum) sebagai anti nyeri. Journal of Pharmaceutica Sciences, 14.

[4] Saputri M. Evaluasi Mutu Krim Betametason 0, 1\% Produksi PT. Kimia Farma (Persero) Tbk. 2008.

[5] Widodo H. Ilmu Meracik Obat untuk Apoteker. Yogyakarta: D-Medika. 2013.

[6] Safitri, M., Zaky, M., \& Erawati, E. (2016). Pengembangan Formulasi Dan Evaluasi Fisik Sediaan Krim Ekstrak Etanol 70\%. Farmagazine, Vol. III : 7 - 17.

[7] Sharon, N., Anam, S., \& Yuliet. (2013). Formulasi Krim Ekstrak Etanol Bawang Hutan [Eleutherine palmifolia L. (Merr)]. Online Jurnal of Natural Science, Vol 2 (3) : 111-122.

[8] Wulandari, Putri. (2016). Uji Stabilitas Fisik dan Kimia Sediaan Krim Ekstrak Etanol Tumbuhan Paku (Nephrolepis falcate (Cav.)C.Chr.). Skripsi. Fakultas Kedokteran dan Ilmu Kesehatan. Program Studi Farmasi. UIN Syarif Hidayatullah Jakarta.

[9] Suryani., P. A. (2017). Formulasi dan Uji Stabilitas Sediaan Gel Ekstrak Terpurifikasi Daun Paliasa (Kleinhovia Hospita L.) yang Berefek Antioksidan. PHARMACON 6 (3), 157-169.

[10] Depkes Republik Indonesia. (2006). Monografi Ekstrak Tumbuhan Obat Indonesia Volume 2. Jakarta: BPOM Republik Indonesia.

[11] Nuralifah, Armadany, F. I., Parawansah, \& Pratiwi, A. (2018). Uji Aktivitas Antibakteri Sediaan Krim Anti Jerawat Ekstrak Etanol Terpurifikasi Daun Sirih (Piper betle L.) dengan Basis Vanishing Cream Terhadap Propionibacterium acne. Jurnal Farmasi, Kendari : Universitas Halu Pleo.

[12] Mawarni, F, N, A. (2018). Formulasi Krim Ekstrak Etanol Daun Salah Syzygium Polyanthum (Wight) Walp.) Dan Uji Aktivitas Antioksidan Dengan Metode DPPH. Skripsi. Universitas Setia Budi Surakarta.

[13] Lamaga, F, E., Nazila, H., Fitri, R., Putri, F, M, S. Uji Sifat Fisik Dan Uji Aktivitas Antibakteri Krim Ekstrak Etanol Rimpang Rumput Teki Terhadap Bakteri Staphylococcus Aureus. Jurnal Kesehatan Madani Medika 10(1) 20-26. Yogyakarta.

[14] Dermawan, A, M., Pratiwi, L., Kusharyanti, I. (2015). Efektivitas Krimantijerawat Ekstrak Methanol Daun Pacar Air (Impatients balsamina L.). Traditional Medicin Journa. 20(3) 127-133. Tanjungpura University.

[15] Genatrika, E., Nurkhikmah, I., \& Hapsari, I. (2016). Formulasi Sediaan Krim Minyak Jintan Hitam (Nigella Sativa L.) Sebagai Antijerawat Terhadap Bakteri Propionibacterium Acnes. Jurnal, Purwokerto : Universitas Muhammadiyah Purwokerto. 